\title{
Experimental Analysis and Optimization of Cutting Parameters for the Surface Roughness in the Facing Operation of PMMA Material
}

\author{
M. R. Dhakad, K. A. Mahajan, A. C. Mitra \\ (Department of Mechanical Engineering, Modern Education Society's College of Engineering, Pune, India)
}

\begin{abstract}
Poly Methyl Methacrylate (PMMA) is one of the common materials used in optical applications. PMMA is highly transparent to the visible light. The optics required the best surface finish for the maximum transmission of light and to avoid the scattering of light. The best surface finish can be achieved by machining PMMA at optimized parameters. In this paper, the effect of cutting parameters on surface finish is experimentally studied. Facing operation is performed on the PMMA material. The operation is performed on the CNC lathe machine. Three level full factorial design approach is used to for the experimentation. Cutting speed, feed rate and depth of cut are selected as a influencing parameters. Tungsten carbide cutting tool is used for the cutting operation. Surface roughness of the all the specimen is measured by using Talysurf. The optimized cutting parameters combination is found out using ANOVA and regression analysis. The optimum values of parameters to obtain the best surface finish is the $274.89 \mathrm{~m} / \mathrm{min}$. cutting speed, feed rate is $0.05 \mathrm{~mm} / \mathrm{rev}$. and $0.1 \mathrm{~mm}$ depth of cut.
\end{abstract}

Keywords - PMMA, facing operation, tungsten carbide tool, surface roughness, ANOVA

\section{INTRODUCTION}

Poly methyl methacrylate (PMMA) is used in optical operations and its use is continuously increasing day by day. They are used in car lights, traffic lights, contacts lenses, spectacle lenses, laser lenses, eye lenses, micro-structured arrays etc. All the applications mentioned above require high quality or super finish surface profile. Many parameters such as cutting speed, feed rate, depth of cut, nose radius, rake angle, work piece and tool material properties, vibrations etc. influence on the surface finish of material [1]. Hence the optimization of these parameters is very important to get the high quality surface finish. Poly methyl methacrylates (PMMA) are polymers of the esters of methacrylic acids. It is a clear, colorless polymer available on the market. It is commonly called acrylic glass or simply acrylic or Plexiglas [2]. The surface profile quality of any material is measured in terms of roughness. There are various parameters used for the measurements of surface roughness, but $R_{a}$ is the most common in the industry.Researchers worked on the various materials with different machining conditions. S. S Jachak et. al [1] tried to evaluate the effect of cutting variables on surface roughness in plain turning of medium carbon steel AISI 1055. Cutting speed, depth of cut, feed rate and cutting flow rate are selected as the influencing parameters. M.Y. Ali et. al [3] has studied the vibration problems in micro end milling of poly methyl methacrylate (PMMA) workpiece material by using the control parameters like spindle speed, feed rate and depth of cut. They used integrated multi-process machine tools DT 110 (Mikrotools Inc., Singapore). The vibration was measured using accelerometer. After analysis, it is concluded that; the feed rate and depth of cut have highest influence compared to spindle speed on vibration. M. Riedl. [4] has explained the all the detail procedure of single point diamond turning use, advantages and its limitations during operations. He has also suggested some possible improvements during machining. C. Dileep Kumar et al. [5] has done the turning of Ti-6Al-4V and focused on an experimental study to find the effects of cutting parameters on surface finish and optimize them for better surface finish and high Material Removal Rate (MRR). ANOVA is used to find out contribution of each parameter. G. D Mello et al. [6] discussed the application of the Response Surface Methodology (RSM) and Artificial Intelligence (AI) based techniques namely Artificial Neural Network (ANN) and Adaptive Neuro-Fuzzy Inference System (ANFIS) for predicting surface roughness in high speed machining operations. J.W.Carr et al [7] studied the surface structure and roughness of the work piece by using the fundamentals of polymer mechanics. 


\section{DESIGN OF EXPERIMENT}

Design of Experiment approach is selected for investigating the effect of varying controllable parameters [8]. Design of experiments is a mathematical method used to find out the most influencing parameter in the process. It also optimizes the influencing parameters to give best output results. To investigate the cutting parameters, a pilot experimentation is carried out on PMMA. The aim of the pilot experimentation is to set the range of cutting parameters. The pilot experimentation is shown in Table 1. In the Table 1, it is observed that the surface roughness is very poor.

Table 1: Pre-Experimentation

\begin{tabular}{|l|l|l|l|l|}
\hline Run order & $\begin{array}{l}\text { Cutting Speed } \\
(\mathrm{m} / \mathrm{min} .)\end{array}$ & $\begin{array}{l}\text { Feed Rate } \\
(\mathrm{mm} / \mathrm{rev} .)\end{array}$ & $\begin{array}{l}\text { Depth of Cut } \\
(\mathrm{mm})\end{array}$ & $\begin{array}{l}\text { Surface Roughness }\left(\mathrm{R}_{\mathrm{a}}\right) \\
\mu \mathrm{m}\end{array}$ \\
\hline 1 & 40 & 0.1 & 0.1 & 0.523 \\
\hline 2 & 40 & 0.15 & 0.1 & 0.519 \\
\hline 3 & 40 & 0.2 & 0.1 & 0.618 \\
\hline 4 & 40 & 0.1 & 0.05 & 0.509 \\
\hline 5 & 40 & 0.1 & 0.15 & 0.605 \\
\hline 6 & 30 & 0.2 & 0.05 & 0.639 \\
\hline 7 & 50 & 0.2 & 0.05 & 0.699 \\
\hline
\end{tabular}

To get the good values of surface finish, the range of parameters of the machining process is as shown in Table 2. The optimization is done by three level full factorial method. Cutting Speed, feed rate and depth off cut are selected as a influencing parameters by considering all other parameters such as tool nose radius, rake angle, side cutting edge angle etc. constant. Table 3 showing the parameters and their levels considers in the experimentation. Three level of each parameter is considered. Hence the total runs are 27.

Table 2: Range of Parameters

\begin{tabular}{|ll|l|l|}
\hline Parameters & Minimum Values & Maximum Values \\
\hline Cutting speed (m/min) & $\boldsymbol{x}_{\mathbf{1}}$ & 157.08 & 274.89 \\
\hline Feed rate (mm/rev.) & $\boldsymbol{x}_{\mathbf{2}}$ & 0.01 & 0.1 \\
\hline Depth of cut $(\mathbf{m m})$ & $\boldsymbol{x}_{\mathbf{3}}$ & 0.05 & 0.15 \\
\hline
\end{tabular}

\section{EXPERIMENTATION}

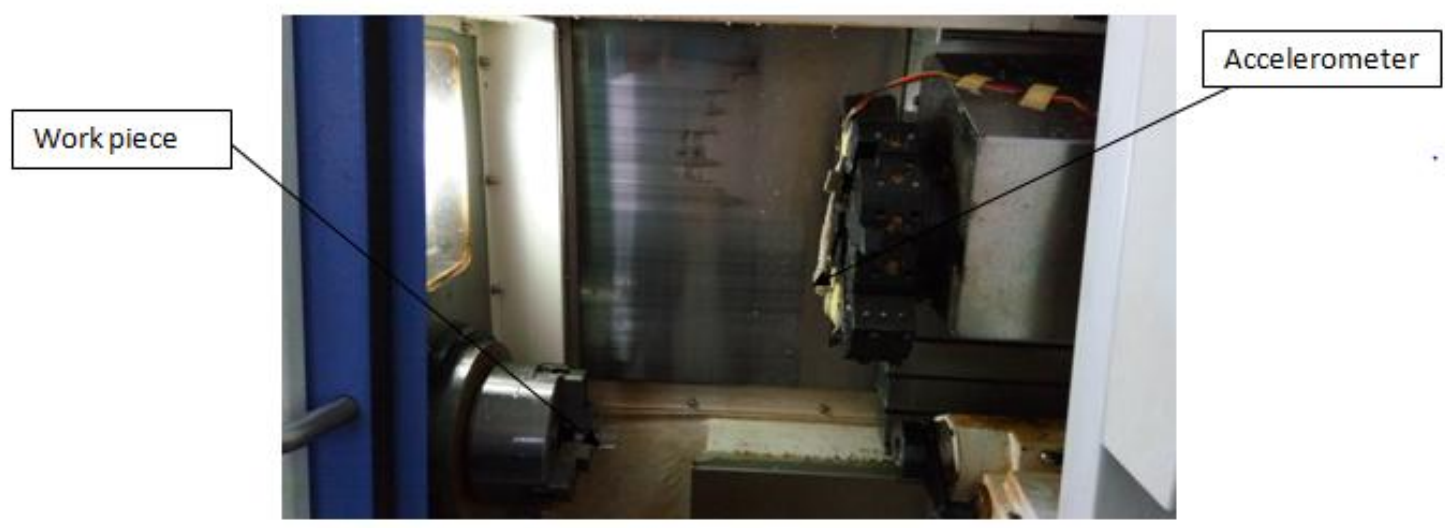

Fig.1 Experimental Set up

The experimental setup consists of CNC lathe machine, tool holder, insert and Talysurf as shown in Fig 1. The experimentation is performed in the CNC lab of Modern Education Society's College of Engineering, Pune. CNC machine is a two axis machine. Its model number is DX 150. The technical specifications of CNC lathe machine are shown in Table 5. Tool holder used is MTJNL 2020 WIDAX K16. The tungsten carbide insert is used for the facing operations of the PMMA material. The insert model is TNMG 160404-HM.

After deciding the parameters and their levels, we find the array of the experimental values. The combination of actual values drawn from the array is shown in Table 4. 
Experimental Analysis and Optimization of Cutting Parameters for the Surface Roughness in the...

Table 4: Combination of actual values of parameters

\begin{tabular}{|l|l|l|l|}
\hline $\begin{array}{l}\text { Run } \\
\text { Order }\end{array}$ & $\begin{array}{l}\text { Cutting } \\
\text { Velocity } \\
(\mathrm{m} / \mathrm{min} .)\end{array}$ & $\begin{array}{l}\text { Feed Rate } \\
(\mathrm{mm} / \mathrm{rev})\end{array}$ & Depth of Cut(mm) \\
\hline 1 & 157.08 & 0.01 & 0.05 \\
\hline 2 & 157.08 & 0.01 & 0.1 \\
\hline 3 & 157.08 & 0.01 & 0.15 \\
\hline 4 & 157.08 & 0.05 & 0.05 \\
\hline 5 & 157.08 & 0.05 & 0.1 \\
\hline 6 & 157.08 & 0.05 & 0.15 \\
\hline 7 & 157.08 & 0.1 & 0.05 \\
\hline 8 & 157.08 & 0.1 & 0.1 \\
\hline 9 & 157.08 & 0.1 & 0.15 \\
\hline 10 & 235.62 & 0.01 & 0.05 \\
\hline 11 & 235.62 & 0.01 & 0.1 \\
\hline 12 & 235.62 & 0.01 & 0.15 \\
\hline 13 & 235.62 & 0.05 & 0.05 \\
\hline 14 & 235.62 & 0.05 & 0.1 \\
\hline 15 & 235.62 & 0.05 & 0.15 \\
\hline 16 & 235.62 & 0.1 & 0.05 \\
\hline 17 & 235.62 & 0.1 & 0.1 \\
\hline 18 & 235.62 & 0.1 & 0.15 \\
\hline 19 & 274.89 & 0.01 & 0.05 \\
\hline 20 & 274.89 & 0.01 & 0.1 \\
\hline 21 & 274.89 & 0.01 & 0.15 \\
\hline 22 & 274.89 & 0.05 & 0.05 \\
\hline 23 & 274.89 & 0.05 & 0.1 \\
\hline 24 & 274.89 & 0.05 & 0.15 \\
\hline 25 & 274.89 & 0.1 & 0.05 \\
\hline 26 & 274.89 & 0.1 & 0.1 \\
\hline 27 & 274.89 & 0.1 & 0.15 \\
\hline & & & \\
\hline & & & \\
\hline
\end{tabular}

Table 5: Technical Specifications of CNC [DX-150 machine]

\begin{tabular}{|l|l|}
\hline Max. Turning length & $350 \mathrm{~mm}$ \\
\hline Max. Turning Diameter & $250 \mathrm{~mm}$ \\
\hline Std. Turning Diameter & $150 \mathrm{~mm}$ \\
\hline X- axis travel & $150 \mathrm{~mm}$ \\
\hline Z- axis travel & $350 \mathrm{~mm}$ \\
\hline X-Z axis travel & $24 \mathrm{M} / \mathrm{min}$. \\
\hline Spindle bore & $50 \mathrm{~mm}$ \\
\hline Spindle speed range & $50-4500 \mathrm{rpm}$ \\
\hline Full power speed range & $1333-3666 \mathrm{rpm}$ \\
\hline Tool size & $20 \times 20 \mathrm{~mm}$ \\
\hline Positioning & $0.015 \mathrm{~mm}$ \\
\hline Machine Height & $1950 \mathrm{~mm}$ \\
\hline Floor space & $1950 \times 1375 \mathrm{~mm}$ \\
\hline
\end{tabular}

The tungsten carbide insert is used for the facing operations of the PMMA material. The insert model is TNMG 160404-HM. The properties of tungsten Carbide Insert are given in Table 6. The cylindrical rod PMMA material is cut into 27 pieces of equal size on the CNC lathe machine. The dimension of each specimen is $25 \mathrm{~mm}$ diameter and 40mm in length as shown in Fig.2.

Table 6: The properties of the Tungsten carbide insert

\begin{tabular}{|l|l|l|}
\hline Property & Value & Unite(S.I) \\
\hline Density & 15.88 & $\mathrm{Mg} / \mathrm{m}^{3}$ \\
\hline Bulk Modulus & 400 & $\mathrm{GPa}$ \\
\hline Compressive Strength & 6833 & $\mathrm{MPa}$ \\
\hline Elastic Limit & 530 & $\mathrm{MPa}$ \\
\hline Ductility & 0.0074 & \\
\hline Endurance Limit & 420 & $\mathrm{MPa}$ \\
\hline
\end{tabular}




\begin{tabular}{|l|l|l|}
\hline Fracture Toughness & 3.8 & $\mathrm{MPa} \cdot \mathrm{m}^{1 / 2}$ \\
\hline Hardness & 36000 & $\mathrm{MPa}$ \\
\hline Poisson's Ratio & 0.22 & \\
\hline Tensile Strength & 530 & $\mathrm{MPa}$ \\
\hline Young's Modulus & 686 & $\mathrm{GPa}$ \\
\hline Latent Heat of Fusion & 560 & $\mathrm{~kJ} / \mathrm{kg}$ \\
\hline Maximum Service Temperature & 1050 & $\mathrm{~K}$ \\
\hline Latent Heat of Fusion & 560 & $\mathrm{~kJ} / \mathrm{kg}$ \\
\hline Melting Point & 3193 & $\mathrm{~K}$ \\
\hline Specific Heat & 292 & $\mathrm{~J} / \mathrm{kg} . \mathrm{K}$ \\
\hline Thermal Conductivity & 88 & $\mathrm{~W} / \mathrm{m} . \mathrm{K}$ \\
\hline Thermal Expansion & 7.1 & $10^{-6} / \mathrm{K}$ \\
\hline
\end{tabular}

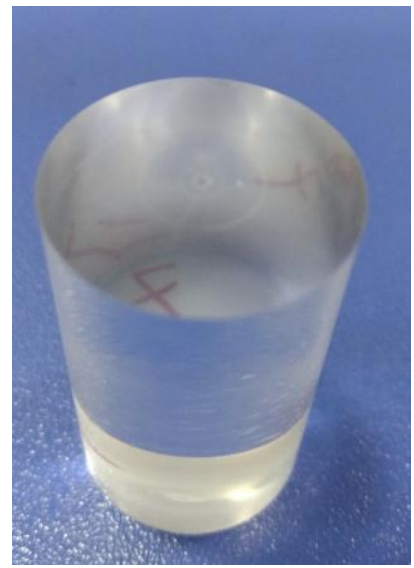

Fig. 2 Specimen of PMMA material

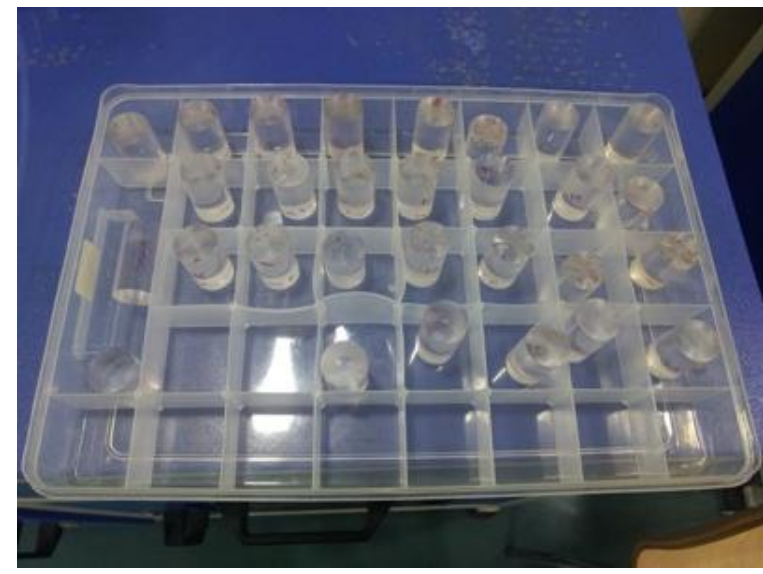

Fig. 3 All samples of equal sizes

The physical, mechanical and optical properties of PMMA material are as given in Table 7, 8 and 9 respectively.

Table 7: Physical Properties [2]

\begin{tabular}{|l|l|}
\hline Properties & Value \\
\hline Density & $1.15-1.19 \mathrm{~g} / \mathrm{cm} 3$ \\
\hline Water Absorption & $0.3-2 \%$ \\
\hline Moisture Absorption at Equilibrium & $0.3-0.33 \%$ \\
\hline Linear Mould Shrinkage & $0.003-0.0065 \mathrm{~cm} / \mathrm{cm}$ \\
\hline Melt Flow & $0.9-27 \mathrm{~g} / 10 \mathrm{~min}$ \\
\hline
\end{tabular}

Table 8: Mechanical Properties [2]

\begin{tabular}{|l|l|}
\hline Properties & Value \\
\hline Density & $1.15-1.19 \mathrm{~g} / \mathrm{cm} 3$ \\
\hline Water Absorption & $0.3-2 \%$ \\
\hline Moisture Absorption at Equilibrium & $0.3-0.33 \%$ \\
\hline Linear Mould Shrinkage & $0.003-0.0065 \mathrm{~cm} / \mathrm{cm}$ \\
\hline Melt Flow & $0.9-27 \mathrm{~g} / 10 \mathrm{~min}$ \\
\hline
\end{tabular}

Table 9: Optical Properties [2]

\begin{tabular}{|l|l|}
\hline Properties & Value \\
\hline Hardness, Rockwell & M 63- 97 \\
\hline Tensile Strength, Ultimate & $47-79 \mathrm{Mpa}$ \\
\hline Elongation at Break & $1-30 \%$ \\
\hline Tensile Modulus & $2.2-3.8 \mathrm{Gpa}$ \\
\hline Flexural Modulus & $3-3.5 \mathrm{GPa}$ \\
\hline Tensile Creep Modulus, 1 h & $1800-2700 \mathrm{Mpa}$ \\
\hline Tensile Creep Modulus, 1000 h & $1200-1800 \mathrm{Mpa}$ \\
\hline
\end{tabular}

Talysurf is used for the measurement of surface finish of the component is shown in Fig.4. After facing operation on all 27 specimens, the surface roughness is measured as shown in Fig. 3. The experimental results are shown in Table 10. 


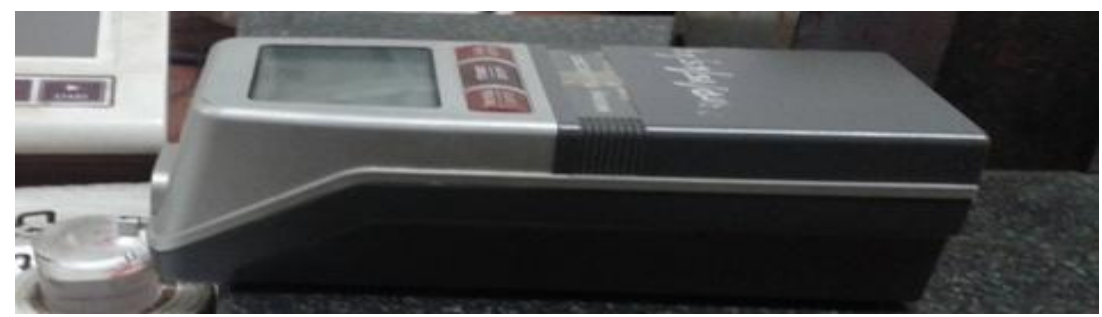

Fig.4 Surface roughness measurement using Talysurf

Table 10: Experimental Results

\begin{tabular}{|l|l|l|l|l|}
\hline Run Order & $\begin{array}{l}\text { Cutting Velocity } \\
(\mathrm{m} / \mathrm{min} .)\end{array}$ & $\begin{array}{l}\text { Feed Rate } \\
(\mathrm{mm} / \mathrm{rev})\end{array}$ & $\begin{array}{l}\text { Depth of Cut } \\
(\mathrm{mm})\end{array}$ & $\begin{array}{l}\text { Surface Finish } \\
(\text { micron })\end{array}$ \\
\hline 1 & 157.08 & 0.01 & 0.05 & 0.108 \\
\hline 2 & 157.08 & 0.01 & 0.1 & 0.08 \\
\hline 3 & 157.08 & 0.01 & 0.15 & 0.09 \\
\hline 4 & 157.08 & 0.05 & 0.05 & 0.24 \\
\hline 5 & 157.08 & 0.05 & 0.1 & 0.18 \\
\hline 6 & 157.08 & 0.05 & 0.15 & 0.27 \\
\hline 7 & 157.08 & 0.1 & 0.05 & 0.24 \\
\hline 8 & 157.08 & 0.1 & 0.1 & 0.243 \\
\hline 9 & 157.08 & 0.1 & 0.15 & 0.223 \\
\hline 10 & 235.62 & 0.01 & 0.05 & 0.07 \\
\hline 11 & 235.62 & 0.01 & 0.1 & 0.06 \\
\hline 12 & 235.62 & 0.01 & 0.15 & 0.065 \\
\hline 13 & 235.62 & 0.05 & 0.05 & 0.133 \\
\hline 14 & 235.62 & 0.05 & 0.1 & 0.193 \\
\hline 15 & 235.62 & 0.05 & 0.15 & 0.2 \\
\hline 16 & 235.62 & 0.1 & 0.05 & 0.25 \\
\hline 17 & 235.62 & 0.1 & 0.1 & 0.2 \\
\hline 18 & 235.62 & 0.1 & 0.15 & 0.18 \\
\hline 19 & 274.89 & 0.01 & 0.05 & 0.05 \\
\hline 20 & 274.89 & 0.01 & 0.1 & 0.05 \\
\hline 21 & 274.89 & 0.01 & 0.15 & 0.08 \\
\hline 22 & 274.89 & 0.05 & 0.05 & 0.1 \\
\hline 23 & 274.89 & 0.05 & 0.1 & 0.09 \\
\hline 24 & 274.89 & 0.05 & 0.15 & 0.23 \\
\hline 25 & 274.89 & 0.1 & 0.05 & 0.22 \\
\hline 26 & 274.89 & 0.1 & 0.1 & 0.233 \\
\hline 27 & 274.89 & 0.1 & 0.15 & 0.22 \\
\hline & & & & \\
\hline & & & & \\
\hline & & & & \\
\hline
\end{tabular}

\section{RESULTS AND DISCUSSIONS}

ANOVA analysis is performed for the surface roughness in order to find out the most influencing parameter affecting these responses. The main effect plot and interaction effects plot of cutting speed, feed rate and depth of cut on surface roughness are drawn.
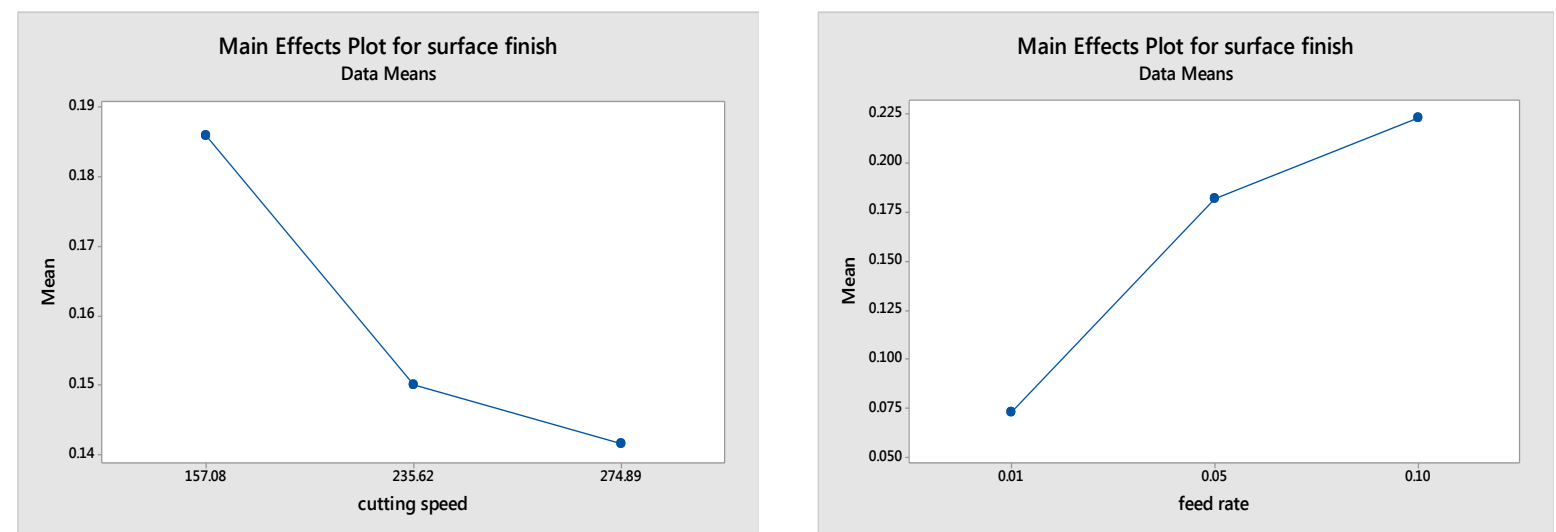

Fig.5 Main Effect plot of Cutting Speed vs Suface Finish, Fig. 6.Main Effect plot of feed Rate vs Surface Finish 
It is observed in the above Fig. 5 that surface roughness value decreases with the increase in cutting speed of the material. It is seen that cutting speed $274.89 \mathrm{~m} / \mathrm{min}$ is the best value for facing of the PMMA Material. The cutting speed must be maximum for the facing operation of PMMA Material. Due to higher cutting speed the interaction time between the work piece material and tool holder is very less. Due to this, the surface roughness of the material is more at higher speed. This may because of the fact that there is continuous reduction in the buildup edge formation for higher cutting speeds. It is also observed in the graph that the change in surface roughness value from start to mid level is more compared to change from midlevel to higher cutting speed

It is clearly seen in the Fig. 6 that surface roughness increases as feed rate increase. The surface roughness depends mainly on feed rate. Theory also suggests roughness to be a function of square of feed rate. The feed rate must be minimum for the facing operation of PMMA material. Due to less feed rate the cutting forces acting on the material are also less which results in less vibration of tool. The tool vibrations and surface roughness of the material are directly proportional to each other. From the graph, it is seen that feed rate 0.01 $\mathrm{mm} / \mathrm{rev}$. is the best value for facing of the PMMA Material. It is also observed from the graph that surface roughness value changes drastically up to mid level but after that change in surface roughness is less compared to initial condition.

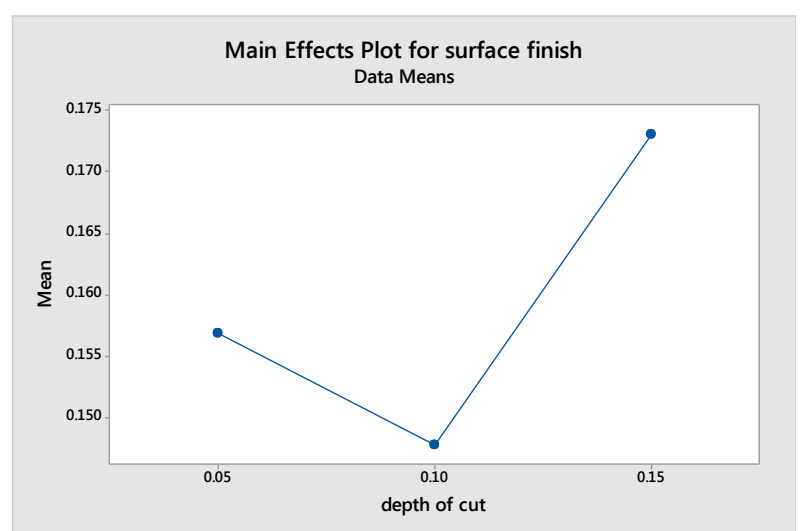

Fig. 7 Main Effect plot of Depth of Cut vs Suface Finish

It is observed in the Fig. 7 that depth of cut also influences on the surface finish of the material. But its effect is less compared to feed rate and cutting speed. It is seen that depth of cut $0.1 \mathrm{~mm}$ is the best value for facing of the PMMA Material. We can also take the minimum value of it i.e. $0.05 \mathrm{~mm}$ because in the graph, it is noticed that as the depth of cut increases, there is no major changes in the values of surface roughness.

The effect of depth of cut on cutting forces is because as the depth of cut increases the volume of the uncut chip also increases which produces more resistance on the cutter, thus increasing the cutting force. But in our case the depth of cut values are too less to do change in surface finish of the material.

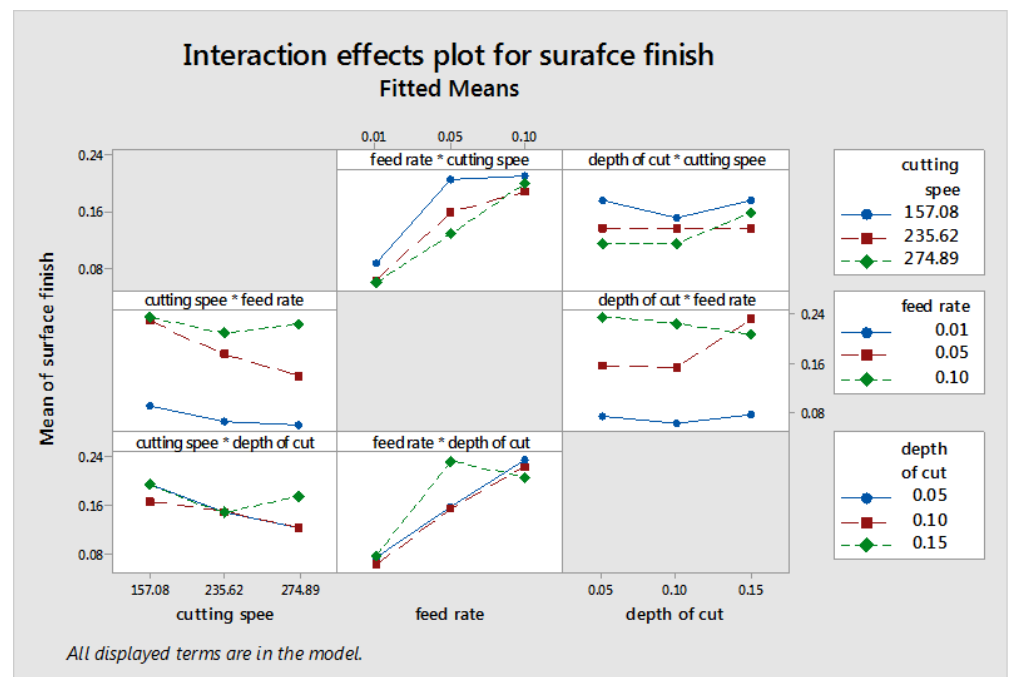

Fig. 8 Combined effect of cutting parameters on Surface Roughness 
The interaction effect of cutting parameters on surface roughness is shown in Fig. 8. In this if we select the cutting speed $157.08 \mathrm{~m} / \mathrm{min}$. then the feed rate value $0.01 \mathrm{~mm} / \mathrm{rev}$. is associated with it to give the minimum value of the surface finish. Similarly, it will vary for the other cutting speeds too. In this if we select the feed rate $0.05 \mathrm{~mm} / \mathrm{rev}$ then the depth of cut $0.10 \mathrm{~mm}$ is associated with it to give the minimum value of the surface finish. Similarly, it will vary for the other feed rates too. In this if we select the cutting speed $235.62 \mathrm{~m} / \mathrm{min}$ then the depth of cut $0.15 \mathrm{~mm}$ is associated with it to give the minimum value of the surface finish. Similarly, it will vary for the other cutting speeds too.

\subsection{Regression Analysis and ANOVA}

In many problems two or more variables are related, and it is of the interest to model and explore their relationship. Regression analysis is used for expressing the results of experiments quantitatively in terms of an empirical model, to facilitate understanding, interpretation and implementations [9]. The regression equation for the surface roughness is obtained by fitting a second order model to analyze the significant machining parameters for various cutting forces and surface roughness.

Regression Equation for surface roughness ( $\mathrm{Ra}$ ) Value is as follows.

Surface finish $(\mathrm{Ra})=0.342-0.00176 v-1.88 \mathrm{~d}+3.92 f+0.000002 v^{2}+6.91 d^{2}-21.13 f^{2}$

Table 11: Regression analysis for surface roughness

\begin{tabular}{|l|l|l|}
\hline R Square & Adjusted R Square & Observations \\
\hline 0.8506 & 0.7715 & 27 \\
\hline
\end{tabular}

The regression analysis for surface roughness is shown in table 10.The value of adjusted $\mathrm{R}$ square is $77.15 \%$ and is a decrease of $9.41 \% \mathrm{R}$ square value indicate that the degree of closeness of variable with best fit line. The value of $\mathrm{R}$ square which is 0.8506 indicates that the degree of closeness of the parameters with the best fitted line is $85.06 \%$. It shows that the parameters are strongly correlated with each other.

Table 12: ANOVA of Surface Roughness

\begin{tabular}{|c|c|c|c|c|c|c|c|}
\hline Source & DF & Adj.SS & Adj. MS & F-Value & $P$ - Value & Contribution & Rank \\
\hline Cutting Speed & 2 & 0.010045 & 0.005022 & 7.53 & 0.014 & 6.81 & 3 \\
\hline Feed Rate & 2 & 0.109043 & 0.054521 & 81.72 & 0.000 & 74.01 & 1 \\
\hline Depth of cut & 2 & 0.002992 & 0.001496 & 2.24 & 0.169 & 2.03 & 6 \\
\hline $\begin{array}{l}\text { Cutting Speed } \times \text { feed } \\
\text { Rate }\end{array}$ & 4 & 0.005118 & 0.001279 & 1.92 & 0.201 & 3.47 & 4 \\
\hline $\begin{array}{l}\text { Cutting } \\
\text { Speed } \times \text { Depth of Cut }\end{array}$ & 4 & 0.004123 & 0.001031 & 1.55 & 0.278 & 2.79 & 5 \\
\hline $\begin{array}{l}\text { Feed RatexDepth of } \\
\text { Cut }\end{array}$ & 4 & 0.010658 & 0.002665 & 3.99 & 0.045 & 7.23 & 2 \\
\hline Error & 8 & 0.025337 & 0.000667 & & & 3.62 & \\
\hline Total & 26 & 0.147316 & & & & & \\
\hline \multicolumn{8}{|l|}{ Model Summary } \\
\hline $\begin{array}{cc}\mathrm{S} & \mathrm{R}-\mathrm{sq} \\
0.0258292 & 96.38 \%\end{array}$ & $\begin{array}{l}-\mathrm{sq}(\mathrm{a} \\
88.2 ?\end{array}$ & $\begin{array}{l}\text { R-sq(pr } \\
58.73 \%\end{array}$ & & & & & \\
\hline
\end{tabular}

A low P-value $(\leq 0.05)$ indicates statistical significance for the source on the corresponding response that is $\alpha=0.05$, or $95 \%$ confidence level. The pie chart in the Fig. 9 is showing the percentage contribution of individual parameter and their interaction effect. The theoretical values of the surface finish are calculated from the equation (1) [10]. This equation is based on the feed rate so the effect of other parameters is not included in the theoretical values. But experimental results are the output of all the parameters like cutting speed, feed rate and depth of cut. The theoretical and Experimental values of surface roughness are shown in Table 12.

$$
R_{a}=\frac{0.0321 f^{2}}{r}
$$



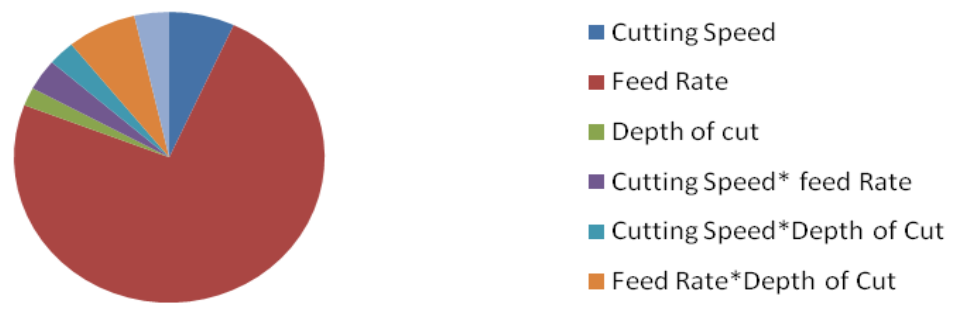

Fig. 9 Percentage Contribution of parameters for Surface roughness

Table 13: Theoretical and Experimental values of Surface Roughness

\begin{tabular}{|c|c|c|}
\hline \multirow{2}{*}{ Run Order } & \multicolumn{2}{|c|}{ Surface Finish $\mathrm{Ra}$ (micron) } \\
\hline & Experimental & Theoretical \\
\hline 1 & 0.108 & 0.008 \\
\hline 2 & 0.08 & 0.008 \\
\hline 3 & 0.09 & 0.008 \\
\hline 4 & 0.24 & 0.2 \\
\hline 5 & 0.18 & 0.2 \\
\hline 6 & 0.27 & 0.2 \\
\hline 7 & 0.24 & 0.8 \\
\hline 8 & 0.243 & 0.8 \\
\hline 9 & 0.223 & 0.8 \\
\hline 10 & 0.07 & 0.008 \\
\hline 11 & 0.06 & 0.008 \\
\hline 12 & 0.065 & 0.008 \\
\hline 13 & 0.133 & 0.2 \\
\hline 14 & 0.193 & 0.2 \\
\hline 15 & 0.2 & 0.2 \\
\hline 16 & 0.25 & 0.8 \\
\hline 17 & 0.2 & 0.8 \\
\hline 18 & 0.18 & 0.8 \\
\hline 19 & 0.05 & 0.008 \\
\hline 20 & 0.05 & 0.008 \\
\hline 21 & 0.08 & 0.008 \\
\hline 22 & 0.1 & 0.2 \\
\hline 23 & 0.09 & 0.2 \\
\hline 24 & 0.23 & 0.2 \\
\hline 25 & 0.22 & 0.8 \\
\hline 26 & 0.233 & 0.8 \\
\hline 27 & 0.22 & 0.8 \\
\hline
\end{tabular}

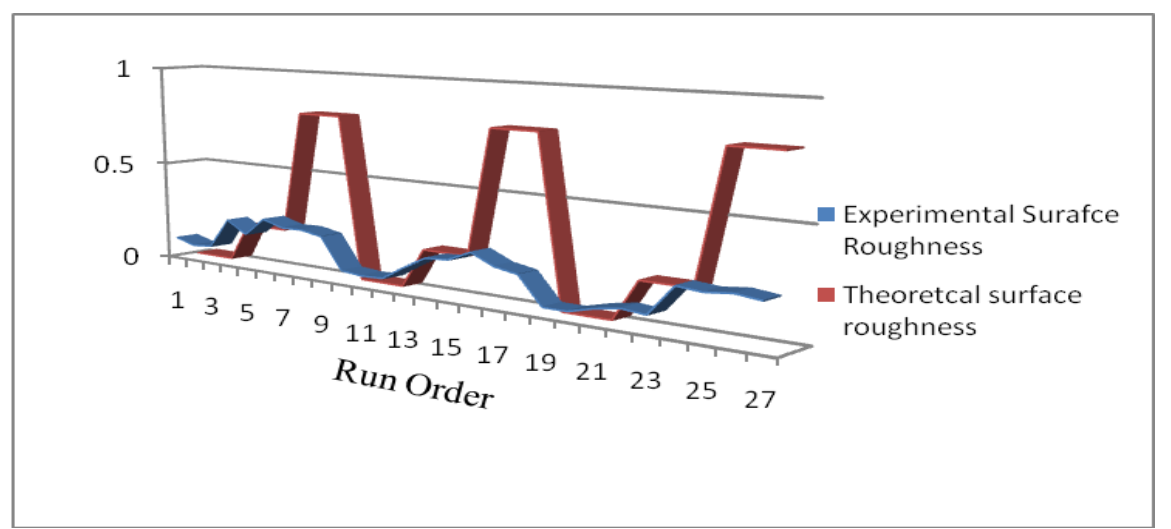

Fig.10 Comparison of theoretical and experimental values of surface finish

From the Fig. 10, it is observed that trend of the graph for both the theoretical and experimental is same. It means that the results obtained through experimentation are right. It is just in scale form. 


\section{CONCLUSION}

The effect of cutting parameters such as cutting speed, feed rate and depth of cut on surface roughness is investigated. The conclusions are as follows.

- The feed rate is the most influencing parameter for the surface roughness followed by the cutting speed and depth of cut. The depth of cut has very negligible effect on the surface roughness of PMMA material.

- For better surface roughness by facing operation of PMMA material the cutting speed should be maximum, feed rate should be minimum and depth of should be moderate. The optimum values of parameters to obtain the best surface finish is the $274.89 \mathrm{~m} / \mathrm{min}$. cutting speed, feed rate is $0.05 \mathrm{~mm} / \mathrm{rev}$. and $0.1 \mathrm{~mm}$ depth of cut.

- Theoretically, we know that feed rate is the most influencing parameter for surface finish. And the same results we obtained here for PMMA material machining.

\section{REFERENCES}

[1] S. S Jachak, V. R. Pandey, Optimization of CNC Turning Process Parameters for Prediction of Surface Roughness by Factorial Experimentation, International Journal of Innovative Research \& Development,3( 3),2014,405-410.

[2] M.Y. Ali, A.R. Mohamed, A.A. Khan, B. Asfana, M. Lutfi and M.I. Fahmi ,Empirical Modelling of Vibration in Micro End Milling of PMMA, World Applied Sciences Journal 21 (Mathematical Applications in Engineering),2013, 73-78.

[3] M. Riedl, Advances in single-point diamond turning provide improved performance for visible as well as in optics, SPIE's OEmagazine, 2004

[4] C. Dileep Kumar, M. Arun , A. K Varughese,Study of Effect of Tool Nose radius on Surface Finish and Optimization of Machining Parameters of Turning Process of an Aerospace Material,4(1),2015,1-10.

[5] G. D. Mello, S. Pai , Prediction of Surface Roughness in High Speed Machining: A Comparison, International Journal of Research in Engineering and Technology, 3(3)2014,519-525.

[6] J.W. Carr, C. Feger, Ultra precision machining of polymers, Precision Engineering,15(4),1993, 221-237.

[7] N. B. Chaudhari, R. N. Yerrawar, Suppression of Machine Tool Vibration Using Passive Damping, International Engineering Research Journal (IERJ),2,2015, 5062-5070.

[8] Design Handbook of Analysis and Experiments, ( Douglas C. Montgomery, $8^{\text {th }}$ Edition, WILEY(Chapter 10))

[9] D. A. Cozzens, P. D Rao, W. W. Olson, J. W. Sutherland, J. Mark Panetta,An Experimental investigation into the effect of cutting fluid conditions on the boring of Aluminium alloys Journal of Manufacturing Science and Engineering,121,1999,434-439. 